\title{
Dentin hassasiyetinin etiyolojisi ve risk faktörleri
}

\author{
Fatma Sağ Güngör ${ }^{\alpha}$, Said Karabekiroğlu ${ }^{\alpha}$
}

Selcuk Dent J, 2017; 4: 28-35

Başuru Tarihi: 20 Subat 2017 Yayına Kabul Tarihi: 23 Mart 2017

\begin{abstract}
öz
Dentin hassasiyetinin etiyolojisi ve risk faktörleri

Dentin hassasiyeti prevalans, etiyoloji ve risk faktörleri açısından geniş bir varyasyona sahip yaygın bir klinik bulgudur. Ekspoze olmuş dentinin termal, buharlaşma, dokunma, elektriksel, osmotik veya kimyasal uyaranlara karşı cevap olarak oluşturduğu ani, keskin ve kısa süreli bir ağrı ile karakterizedir. Dentin hassasiyeti ile ilgili yapılan prevalans çalışmaları çok farklı sonuçlar ortaya koymuştur. Esas olarak, diş minesinin aşınması, sement kaybı ya da dişet çekilmesine bağlı olarak dentin tübüllerinin ağız ortamına açılması sonucu ortaya çıkar. Bu durum ise bireyden bireye değişebilen birçok faktöre bağlı olarak meydana gelmektedir. Bu nedenle doğru bir teşhis ve tedavi planlaması için öncelikle etiyolojik faktörlerin belirlenmesi gerekmektedir. Bu derlemede dentin hassasiyetinin tanımı, prevalansı, mekanizması, etiyolojisi ve risk faktörleri ile klinik tanı ve teşhis yöntemleri anlatılmaktadır.
\end{abstract}

\section{ANAHTAR KELIMELER}

Dentin hassasiyeti, etiyoloji, prevalans

Dentin hassasiyeti; herhangi bir dental defekt ya da patoloji ile açıklanamayan, dişin termal, kimyasal, mekanik ya da osmotik uyarılarla karşılaşması sonucu ekspoze dentin yüzeyinde oluşan akut, ani, keskin ve kısa süreli bir ağrı şeklinde tanımlanmaktadır. ${ }^{1}$ Yani dentin hassasiyeti gerçek bir hastalık değil bir semptomlar kompleksidir.

Termal uyaranlar; sıcak ya da soğuk yiyecek-içeceklerin tüketilmesi, özellikle kış aylarında atmosferik soğuk havanın solunması olabilir. Soğuk, hassasiyete neden olan en genel uyarandır.

Genel mekanik uyaranlar; diş fırçaları, çatal-kaşık gibi yemek aletleri ve dental enstrümanların dişe temasıyla oluşmaktadır. Dental hava spreyinden soğuk hava ya da su püskürtülmesi ve tükürük emici kullanımı hastayı rahatsız edebilir.

Osmotik uyaranlar ise; şekerli ve asitli yiyecek-içeceklerin tüketilmesidir. Asitli uyaranlarda greyfurt, limon gibi asitli meyveler ve içecekler ile ilaçlar (aspirin, vitamin C) yer almaktadır. $^{2}$

Dentin hassasiyeti teşhisini koyabilmek için, ekspoze olmuş dentin yüzeylerinde vital pulpaya uzanan skleroze

\section{ABSTRACT}

Etiology and risk factors of dentine hipersensitivity

Dentin sensitivity is a widespread clinical finding with a wide variation in prevalence, etiology, and risk factors. It is characterized by a sudden, sharp and short-term pain that the exposed dentin produces as a response to thermal, evaporation, tactile, electrical, osmotic or chemical stimuli. Prevalence studies on dentin sensitivity have produced very different results. Mainly, it occurs as a result of exposed dentinal tubules depending on the wearing enamel, loss of cementum and gingival recession. This situation depends on many factors that can vary from individual to individual. Therefore, for proper diagnosis and treatment planning, the etiologic factors should be determined first. In this review, definition, prevalence, mechanism, etiology and risk factors of dentin sensitivity and clinical diagnosis and diagnostic methods are explained.

\section{KEYWORDS}

Dentin hypersensitivity, etiology, prevalence

olmamış açık dentin tübüllerinin bulunması gerekir. Hassas dentinde hassas olmayan dişe göre, 8 kat daha fazla tübül gözlenmiştir ve tübül çapları 2 kat daha geniştir. ${ }^{3-5}$

Kron dentininde kök dentinine göre daha büyük çaplı daha fazla sayıda dentin tübülü vardır. Kronda pulpa boynuzu üzerindeki alanlarda geçirgenlik en fazla iken santral fossanın bulunduğu bölgede en azdır. ${ }^{6}$ Poiseuille'e göre akışkanın hızı tübül genişliğinin dördüncü kuvveti ile doğru orantılıdır. Buna göre açık dentin tübül çapı ve sayısına bağlı olarak hassas dentinde hassas olmayan dentine göre 100 kat daha fazla sıvı akışı olur. ${ }^{3-5}$

Dentin hassasiyetinin teşhisi ve tedavi planlaması hastanın ağrıya karşı verdiği sübjektif tepkilere göre yapılmaktadır. Ağrı eşiği ise kişiden kişiye ve psikolojik faktörlere göre değiştiğinden kesin bir ölçüt olarak kabul edilememektedir. ${ }^{7}$ Son yıllarda, SEM ve mikro analizlerle yapılan incelemeler, araştırmalara daha objektif değerlendirme yöntemleri kazandırsa da klinik muayene ve hasta tepkisinden yararlanmadan doğru sonuca varılamamaktadır. $^{8}$

\footnotetext{
${ }^{\alpha}$ Necmettin Erbakan Üniversitesi Diş Hekimliği Fakültesi Restoratif Diş Tedavisi Anabilim Dalı, Konya
} 


\section{Dentin hassasiyetinin prevalansı}

Dentin hassasiyeti ile ilgili yapılan prevalans çalışmaları \%1.34'den \%98'e varan farklı sonuçlar ortaya koymuştur. $\mathrm{Bu}$ fark; araştırmanın yapıldığı popülasyonun etnik kökenine, ağız hastalıklarına karşı tutumuna, beslenme ve oral hijyen alışkanlıklarındaki farklılıklara, psikolojik faktörlere ve ağrı bildirimlerinin subjektif oluşuna; çalışmada kullanılan araştırma, muayene ve teşhis yöntemlerinin birbirinden farklı olmasına ve hekim ile hasta arasındaki plasebo etkiye bağlanmaktadır. ${ }^{9-16}$ Son yıllarda yayınlanmış çalışmaların yapıldığı ülkeye ve kullanılan yöntemlere göre değişen prevalans değerleri özet olarak Tablo 1'de yer almaktadır.

Tablo 1.

\section{Son yıllarda yayınlanmış çalışmaların yapıldığı ülkeye ve kullanılan yöntemlere göre değişen prevalans değerleri}

\begin{tabular}{|c|c|c|c|c|}
\hline Araştırmacılar & Ülke & $\begin{array}{l}\text { Çalışma } \\
\text { Tipi }\end{array}$ & $\mathbf{n}$ & $\begin{array}{c}\text { Prevalans } \\
\text { (\%) }\end{array}$ \\
\hline Haneet ve Vandana, $2016^{47}$ & Hindistan & $\begin{array}{l}\text { Anket- } \\
\text { Klinik }\end{array}$ & 404 & 20,6 \\
\hline Clement et al., $2015^{48}$ & Nijerya & Anket & 211 & 52,8 \\
\hline Naidu et al., $2014^{49}$ & Hindistan & $\begin{array}{l}\text { Anket- } \\
\text { Klinik }\end{array}$ & 212 & 32 \\
\hline Zakereyya ve Aljamal, $2014^{50}$ & İran & $\begin{array}{l}\text { Anket- } \\
\text { Klinik }\end{array}$ & 1.478 & 28,7 \\
\hline Braimoh ve llochonwu, $2014^{51}$ & Nijerya & Anket & 360 & 63,3 \\
\hline Rane et al., $2013^{52}$ & Hindistan & $\begin{array}{l}\text { Anket- } \\
\text { Klinik }\end{array}$ & 960 & 42,5 \\
\hline Vijaya et al., $2013^{53}$ & Hindistan & $\begin{array}{l}\text { Anket- } \\
\text { Klinik }\end{array}$ & 655 & 55 \\
\hline Khafaji, $2013^{54}$ & Arabistan & $\begin{array}{l}\text { Anket- } \\
\text { Klinik }\end{array}$ & 204 & 27 \\
\hline Cunha-Cruz et al., $2013^{55}$ & USA & $\begin{array}{l}\text { Anket- } \\
\text { Klinik }\end{array}$ & 787 & 12,3 \\
\hline Wang et al., $2012^{56}$ & Çin & $\begin{array}{l}\text { Anket- } \\
\text { Klinik }\end{array}$ & 6.843 & 34,5 \\
\hline Colak et al., 2012a ${ }^{57}$ & Türkiye & $\begin{array}{l}\text { Anket- } \\
\text { Klinik }\end{array}$ & 1.169 & 7,6 \\
\hline Colak et al., 2012b ${ }^{58}$ & Türkiye & Anket & 1.463 & 8,4 \\
\hline Ye et al., $2012^{13}$ & Çin & $\begin{array}{l}\text { Anket- } \\
\text { Klinik }\end{array}$ & 2.120 & 34,1 \\
\hline Bahşi et al., $2012^{59}$ & Türkiye & $\begin{array}{l}\text { Anket- } \\
\text { Klinik }\end{array}$ & 1.368 & 5,3 \\
\hline Amarasena et al., $2011^{60}$ & Avustralya & $\begin{array}{l}\text { Anket- } \\
\text { Klinik }\end{array}$ & 1.149 & 9,1 \\
\hline Bamise et al., $2010^{61}$ & Nijerya & Anket & 1.019 & 68,4 \\
\hline Kehua et al., $2009^{62}$ & Çin & $\begin{array}{l}\text { Anket- } \\
\text { Klinik }\end{array}$ & 1.320 & 25,5 \\
\hline Rees et al., $2003^{63}$ & $\begin{array}{l}\text { Hong } \\
\text { Kong }\end{array}$ & $\begin{array}{l}\text { Anket- } \\
\text { Klinik }\end{array}$ & 226 & 67,7 \\
\hline
\end{tabular}

Dentin hassasiyeti tek dişte ya da birçok diște ortaya çıkabileceği gibi tüm ağızda da görülebilir. Kaninler ve küçük azılar en çok etkilenen dişlerdir. Sıklıkla dişlerin bukkal servikal bölgelerinde gözlenirken herhangi bir dişin herhangi bir yüzeyinde de görülebilir. ${ }^{17}$

Dentin hassasiyeti her yaşta görülebileceği gibi en sık 20-40 yaş aralığında gözlenir. Yapılan araştırmalarda dentin hassasiyetinin genç erişkinlerde maksimum düzeye ulaşıp yaşla birlikte azaldığı bildirilmiştir. ${ }^{18}$ Çünkü ileri yaşlarda pulpanın damar ve sinir dallanmaları azalmaktadır. Ayrıca sekonder ve tersiyer dentin oluşumuna bağlı olarak dentin skleroze olmakta ve dentin kanallarının daralmasıyla birlikte hidroksiapatit kristallerinin çökelmesi sonucu kanallar tıkanarak geçirgenlik azalmaktadır. ${ }^{19,20}$

Kadınlarda erkeklere göre daha yüksek oranda dentin hassasiyeti gözlemlenmiştir. Bu durumun sebebi, kadınların ağız hijyen uygulamalarını idealden fazla sıklıkta ve kuvvetle uygulamalarına bağlanmıştır.

Dentin hassasiyeti görülen hastaların oral hijyen uygulamalarında güçlükler yaşayabileceği ve yetersiz plak kontrolü sonucu hassasiyetin daha da şiddetlenebileceği öne sürülmüştür. Çünkü hasta diş fırçasını ağrılı bölgeye uygulayamadığından plağı dişlerinden uzaklaştıramamakta ve periodontal problemlere yol açabilmektedir. Yani periodontal problemler sonucu dişeti çekilmesiyle birlikte sementin açığa çıkmasıyla hassasiyet artabilmektedir. ${ }^{21}$ Ayrıca küretaj ve kök düzeltme işlemleri sırasında sadece debrisleri elimine etmekle kalmayıp sement ve yüzeyel dentinin de uzaklaşmasına bağlı olarak periodontal tedaviden hemen sonra dentin tübülleri ekspoze olabilmekte ve hassasiyet görülme oranı yükselebilmektedir. ${ }^{3}$

Yapılan bir çalışmada, diş fırçalama döngüsü süresince ilk fırçalanan dişin son fırçalanan dişe göre daha uzun süre fırçalandığı bildirilmiştir. Buna göre firçalamaya başlanan dişlerde hassasiyet görülme sıklığının yükseldiği düşünülmektedir. ${ }^{22}$

Ayrıca; sağ elini kullananların sol tarafındaki dişlerde, sol elini kullananların ise sağ tarafındaki dişlerde daha fazla hassasiyet oluştuğu gözlenmiştir. Bu durumun, kullanılan el ile ters taraftaki dişlerin bukkal yüzeylerinin daha etkin fırçalanması sonucu oluştuğu bildirilmiştir. ${ }^{17,23}$ 
Dentin hassasiyeti oluşum mekanizmalarına ait teoriler

Dentin hassasiyetinin oluşmasındaki temel mekanizma, uyaranların etkisiyle tübül içerisindeki dentin sıvısının hareket etmesi ve $\mathrm{A}$ liflerinin aktivasyonu sonucu gerçekleşmektedir. Fakat dentine gelen bir uyarının pulpa-dentin sınırındaki duyusal reseptörlere nasıl taşındığı halen tam olarak bilinmemektedir. Bu konuyla alakalı üç teori öne sürülmüştür. Bunlar:

1. Odontoblast Reseptör Teorisi

2. Doğrudan Sinir Sonlanması Teorisi

3. Hidrodinamik Teori

$\mathrm{Bu}$ teorilerden en çok kabul gören Hidrodinamik Teoridir. ${ }^{24}$ Diğer iki teori ise bazı araştırma ve çalışmalar sonucu geçerliliğini yitirmiş gibi gözükmektedir.

\section{Odontoblast reseptör teorisi}

$\mathrm{Bu}$ teoriye göre, dentin tübülleri içerisindeki odontoblast uzantıları reseptör görevi görür. Mekanik ya da kimyasal uyarılar nörotransmitterlerin salınmasına neden olur ve uyarılar sinir uçlarına iletilir. Ancak yapılan çalışmalarda odontoblast uzantılarının nörotransmitter salgılamadığı ve odontoblastlar zarar görse bile pulpada his kaybı oluşmadığı görülmüştür. ${ }^{18,26} \mathrm{Bu}$ nedenle odontoblastların duyu reseptörü olarak görev yaptığı ve dentin hassasiyetinde rol oynadığı teorisi reddedilmiştir.

\section{Doğrudan sinir sonlanması teorisi}

Bu teori mekanik, kimyasal ya da termal stimulusların, pulpadaki sinir lifleriyle direkt bağlantılı olan odontoblast uzantılarını doğrudan uyarması sonucu ağrı oluşturduklarını savunmaktadır. ${ }^{18}$

Fakat bu teorinin geçerliliği de kabul görmemiştir. Çünkü dentin tübülleri içerisinde sinir uzantıları yer alsa bile bu uzantılar mine-dentin sınırına kadar ulaşamamaktadır.

Ayrıca tübüller içindeki odontoblast uzantılarının doğrudan uyarılması sonucu ağrı oluşuyor olsaydı, ekspoze dentin yüzeyine lokal anestezik uygulaması sonucu ağrının kesiliyor olması gerekirdi. Ancak yapılan bir çalışmada anesteziklerin ağrıyı kesmediği gösterilmiş ve bu görüş de dentin hassasiyeti oluşum mekanizmasını tam olarak açıklayamamıştır.

\section{Hidrodinamik teori}

Dentin hassasiyeti için bugüne kadar en çok kabul gören teori, Brannström ve arkadaşları tarafından önerilen hidrodinamik teoridir.

Aslında ilk kez 1955'te Kramer tarafından ortaya atılmıştır. ${ }^{26}$ Kramer, dentin tübül duvarlarının rijit bir yapıda ve içerisinin sıvı bir materyalle dolu olduğu fikrini öne sürmüştür. Bu düşünceye göre periferal uyaranlar tübül içerisindeki sıvının hareketi sonucu pulpaya iletilirler. Ağrıya neden olan kimyasal, mekanik ve termal uyaranlar sonucu dişte meydana gelen in vivo değişiklikleri inceleyen ve bu uyaranların tübül içerisindeki sıvının hareketinde meydana getirdiği değişiklikleri in vitro olarak değerlendiren kişi Brannström'dur. ${ }^{27}$

Bu teori; termal, fiziksel ya da osmotik değişiklikler sonucu ağız ortamına açılmış dentin tübülleri içindeki sıvının her iki yöne doğru hareket etmesi ve bu hareketin de pulpa-dentin sınırındaki duyusal baroreseptörlerin aktivasyonuna neden olması temeline dayanır. ${ }^{28}$

Soğutma, kurutma, buharlaştırma ve hipertonik kimyasal uyarılar, dentin sıvısının dentin-pulpa kompleksinden uzaklaşmasına; yani ağız ortamına doğru akmasına neden olur ve ağrı artışına yol açar. Isı ise pulpaya doğru hareket ettirir. Çünkü ısı hariç diğer tüm uyaranlar tübüllerde büzülmeye yol açarken ısı genleşmeye neden olur.

Yapılan çalışmalarda dentin hassasiyeti görülen hastaların yaklaşık \% 75'inde soğuk uyaranlara yanıt olarak ağrı geliştiği gözlemlenmiştir. ${ }^{29-31}$

Hidrodinamik mekanizmada rol oynayan sinir fibrilleri A-Delta lifleridir. Bu lifler kısa süreli, ani, keskin ve lokalize edilebilen ağrıdan sorumludurlar. C liflerinin uyarılması ile oluşan pulpal ağrı ise saatlerce veya dakikalarca sürebilir, daha yaygındır ve lokalize etmek zordur. ${ }^{32}$

Hassas dentindeki tübül sayısı, hassas olmayan dentin tübüllerinin sayısından sekiz kat daha fazladır. Ayrıca hassas dentinin tübül çapları, hassas olmayan dentinin tübül çaplarından daha geniştir. Yani çap genişledikçe dentin lenfinin akış hızı artar ve bu sebeple hassasiyet oranı da yükselir. Bu da stimulus iletimini hidrodinamik teoriyle açıklayan hipotezi desteklemektedir. 4,5,30,33

Dentin hassasiyetinin etiyolojisi ve risk faktörleri

Dentin hassasiyetinin multifaktöriyel bir etiyolojisi vardır. Temel sebebi; canlı pulpaya uzanan, skleroze olmamış tübüllerin bulunduğu dentin dokusunun ağız ortamına açılmış olmasıdır. Yani ekspoze dentin bulunan tüm bireylerde hassasiyet oluşacağını düşünmek yanlış olacaktır. Çünkü açığa çıkmış her dentin tabakasında açık tübül ağızları bulunmayabilir. Ekspoze dentin yüzeyinin ve dentinden geçecek olan ajanın molekül büyüklüğü, sklerotik ve tamir dentininin oluşumu ve kalan dentin tabakasının kalınlığı da dentin hassasiyetinin ortaya çıkmasını etkileyen faktörlerdendir. Ayrıca hastanın yaşı, ağrı eşiği, psikolojik ve fizyolojik durumu ile tükürük içeriği gibi hastaya bağlı etkenler de önemli rol oynamaktadır. ${ }^{34}$ 
Dentinin ağız ortamına açımasında;

- Minenin aşınması

- Dişeti çekilmesi ve sement kaybı

- Her iki nedenin kombinasyonu etkilidir. ${ }^{35}$

Atrizyon, abrazyon, erozyon ve abfraksiyon, mine tabakasının aşınıp dentinin açığa çıkmasına neden olan çürüksüz servikal lezyonlardır. (NCCL)

Atrizyon; çiğneme sırasında olduğu gibi dişlerin birbirleriyle temasından kaynaklanan fizyolojik bir aşınmadır. İnsizal, okluzal ve nadir olarak proksimal yüzeylerde gözlenir. Okluzal fonksiyonla ilişkili olduğundan bruksizm gibi parafonksiyonel alışkanlıklar nedeniyle şiddetlenebilir. ${ }^{20,36,37}$

\begin{abstract}
Abrazyon; sıklıkla üst çene kanin ve premolar dişlerin servikal yüzeylerinde, yabancı bir cisim aracılığıyla oluşan kama şeklindeki aşınmalardır. Özellikle eroziv asit atağı sonrasında yapılan agresif fırçalama sonucu diş fırça abrazyonu görülebilir. Ayrıca yüksek düzeyde aşındırıcı materyal içeren diş macunlarını uzun süre kullanmak ve pipo içmek gibi alışkanlıklar da abrazyona sebep olabilir.2,20,36
\end{abstract}

Erozyon; iç ve dış kaynaklı asitlerle diş dokularında meydana gelen kimyasal çözünmedir. Asitli ve karbonatlı içecekler ile asit içeren meyveler diyete bağlı dış kaynaklı asitlere örnektir. Reflü gibi gastroözofageal rahatsızlıklar, kronik alkolizm ve blumia nevroza gibi hastalıklar ise iç kaynaklı asit oluşumuna sebep olurlar. Eroziv diş aşınmasındaki ilk aşama minenin asitle demineralizasyonu sonucu yumuşamasıdır. Yumuşayan dişler 1-2 saat içerisinde tükürük veya florürlü bileşiklere maruz kalırsa aşınma geriye döner ve dişlerin yüzeyinde yeniden sertleşme gözlenir. Eğer yumuşamış mineye korunmasız haldeyken herhangi bir sürtünme veya abraziv kuvvet etki ederse kalıcı eroziv lezyonlar oluşabilir. ${ }^{38,39}$

Abfraksiyon; okluzal bölgeye gelen baskı ve gerilim kuvvetleri sonucu servikal bölgenin zayıflamasıyla meydana gelen çatlak ve kırıklardır. Ayrıca abrazyon ve erozyon için predispozan faktör olarak rol oynar. ${ }^{4,20}$

Atrizyon, abrazyon, erozyon ve abfraksiyon tek başlarına mine ve sementin aşınmasında etkilidirler, bununla beraber kombinasyonları çok daha ciddi aşınmalara sebep olurlar. Kenarları keskin sınırlı lezyonlar diş fırçalamaya bağlı abrazyonlarda ve/veya abfraksiyonda gözlenirken, tabak şeklindeki geniş ve sığ lezyonlar erozyon sonucu oluşur.

Asitli gıdaların tüketim sıklığı ile ilgili olarak hastanın diyeti bir süre izlenmeli ve gerekli tavsiyeler hastaya sunulmalıdır. Asitli yiyecekleri tükettikten sonra ağzın suyla çalkalanması, süt gibi alkalin ya da en azından nötr gıdaların tüketilmesi önerilmelidir. Hastaya aşındırıcı diş macunlarını kullanmaktan kaçınması, asitli içecek veya gıdaları tükettikten sonra, diş fırçası aşınmasına asidik erozyonun agonist etkisi nedeniyle en az bir saat fırçalama yapmaması söylenmelidir. ${ }^{31,40}$
Dentin hassasiyetinin bir diğer sebebi de dişeti çekilmesi sonucu kökün açığa çıkması ve sonrasında kök dentini üzerindeki sementin kolayca aşınmasıyla birlikte dentin kanallarının ağız ortamına açılması olarak gösterilebilir.

Diş eti çekilmesi ve sement kaybı aşağıdaki nedenlerle görülebilir:

- Dişin malpozisyonu sonucu incelen bukkal veya lingual alveolar kemikteki rezorbsiyonlar

- Detertraj ve kök düzlemesi, cep eliminasyonu, kron boyu uzatma işlemlerini içeren periodontal cerrahi olmayan tedaviler

- Kronik periodontitis

- Travmatik ya da yetersiz diş fırçalama

- Okluzal bozukluklar

- Kötü alışkanlıklar (dişetini tırnakla itme vb.)

- Dişlerin dental arktaki hatalı pozisyonları

- Hareketli parsiyel protez kroşeleri

- Yüksek frenulum ataçmanları

- Marjinal uyumu bozuk kron ve dolgular

- Yaşla birlikte artan dişeti çekilmeleri

- Ağız bölgesinde piercing kullanımı

Plak kontrolünün etkinliği ile dentin hassasiyeti arasındaki ilişki önemlidir. Yetersiz diş fırçalama sonucunda dental plak birikimi gingival enflamasyona ve periodontal destek doku kaybına neden olur ve kök dentini açığa çıkar. Ekspoze olan dentin bakterilerce oluşturulan asitlere maruz kaldıkça dentin tübüllerinin açıklığı da artar.

Bazı çalışmalar ise plak kontrolü sağlayan bireylerde daha fazla dentin hassasiyeti görüldüğünü bildirmiştir. Fırçalama sırasında dişlere gelen travmatik kuvvetler veya fırçalama sırasında aşırı kuvvet uygulanması, gereğinden uzun süreli diş fırçalama, arayüz temizlik ajanlarının hatalı kullanımı ve abraziv içerikli fazla diş macunu tüketimi dentin dokusunun açığa çıkmasına neden olabilir. ${ }^{2}$

Dentin hassasiyeti periodontitisli hastalarda çok sık gözlenir. Periodontitisli hastalardaki prevalansı \%6098 arasında belirlenmiştir. Periodontal hastalık oluşumuna neden olan kötü ağız hijyeni dişeti çekilmesine de sebep olabilir. Löe ve ark. ağız hijyeni kötü olan hastalardaki dişeti çekilmesinin ağız hijyeni iyi olan hastalara oranla daha fazla olduğunu bildirmiştir. ${ }^{41}$

Tükürük akış hızı ve miktarı, tükürüğün tamponlama kapasitesi ve remineralizasyon potansiyeli dentin hassasiyetinin oluşumunu etkileyen faktörlerdendir. İçeriğindeki bikarbonat, tükürük proteinleri ve kalsiyum fosfatı kullanarak asit ortamı tamponlayabilir; eroziv ajanları dilüe edebilir. Tükürük, kalsiyum ve fosfata doygundur. Normal koşullarda tükürük mineralleri çökelerek dentin tübüllerinin ağızlarını kapatma eğilimindedirler. Bu 
durum dentin hassasiyetinin azalmasındaki mekanizmayı açıklayabilir.

Kserostomi görülen bireylerde bu mekanizma yeterince etkili olamayacak ve hassasiyetin ilerlemesinde risk teşkil edecektir. ${ }^{19,42,43}$

Dentin hassasiyetinin klinik tanı ve teşhis yöntemleri

Dentin hassasiyetinin çok faktörlü oluşu ve semptomlarının diğer dental defekt ve patolojilerle benzerlik göstermesi, klinik tanı ve teşhisini zorlaştırmaktadır. ${ }^{14}$ Dentin hassasiyetinin teşhisinde en sık sondla muayene (Yeaple sondu), hava spreyi ile kurutma ve en çok soğuktan etkilendiği için soğuk testleri kullanılmaktadır. Isırma testi, perküsyon testi, okluzyon değerlendirmesi ve anestezi testi gibi yöntemler de ayırıcı tanıda kullanılmaktadır. ${ }^{44}$

Hekim hastanın hikayesine inanmak zorundadır. Ağrı eşiğinin kişiden kişiye göre farklılık göstermesinden dolayı, aynı ağrı bir hastada yaşam kalitesini düşürürken diğer bir hastada herhangi bir rahatsızığa neden olmayabilir. Bu yüzden hastanın ağrısını objektif bir şekilde ölçmek ve diğer hastalarla karşılaştırmak imkansızdır. ${ }^{5}$

Dentin hassasiyetinin şiddetini ölçmek için en sık tercih edilen skala Vizüel Analog Skala (VAS) ve Sözel Değerlendirme Skalasıdır (VRS).

Detaylı bir klinik muayene ile ayırıcı tanı için diğer dental patoloji ve defektler elimine edildikten sonra, oral hijyen alışkanlıkları ve diyet analizi yapılarak dentin hassasiyeti teşhis edilebilir (Tablo 2).

\section{Dentin hassasiyetinin ayırıcı tanısı}

Diğer dental patoloji ya da defektlerden çoğu dentin hassasiyeti ile benzer özellikler gösterebilmektedir. ${ }^{45}$ Doğru ve detaylı bir klinik ve radyografik muayene sonrası dentin hassasiyeti diğer patolojilerden ayrılır. $\mathrm{Bu}$ patolojiler; çatlak diş sendromu, kırık restorasyonlar, hatalı pin uygulamaları, travmatik okluzyondaki restorasyonlar, diş çürükleri, postoperatif hassasiyet, pulpanın reversible veya irreversible inflamasyonu, restorasyonların kenar sızıntısı, gingival inflamasyon, palatogingival oluklar ve diğer mine invajinasyonları, vital diş beyazlatma uygulamaları olarak sıralanabilir.

"Çatlak Diş Sendromu” ayırıcı tanının en zor yapıldığı klinik durumdur. Ara sıra veya devamlı şiddetli bir ağrı ile karakterizedir. Termal uyaranlardan özellikle soğuğa karşı hassasiyet tipik olarak kendini gösterirken en önemli ayırıcı tanıyı, ağrının çiğneme ile başlaması ve bu durumun dentin hassasiyeti olan çiğneme ile başlaması ve bu durumun dentin hassasiyeti olan dişlerde çok nadir olarak görülmesi oluşturmaktadır. ${ }^{46}$

Tablo 2.

\section{Dentin hassasiyetinin teşhisi}

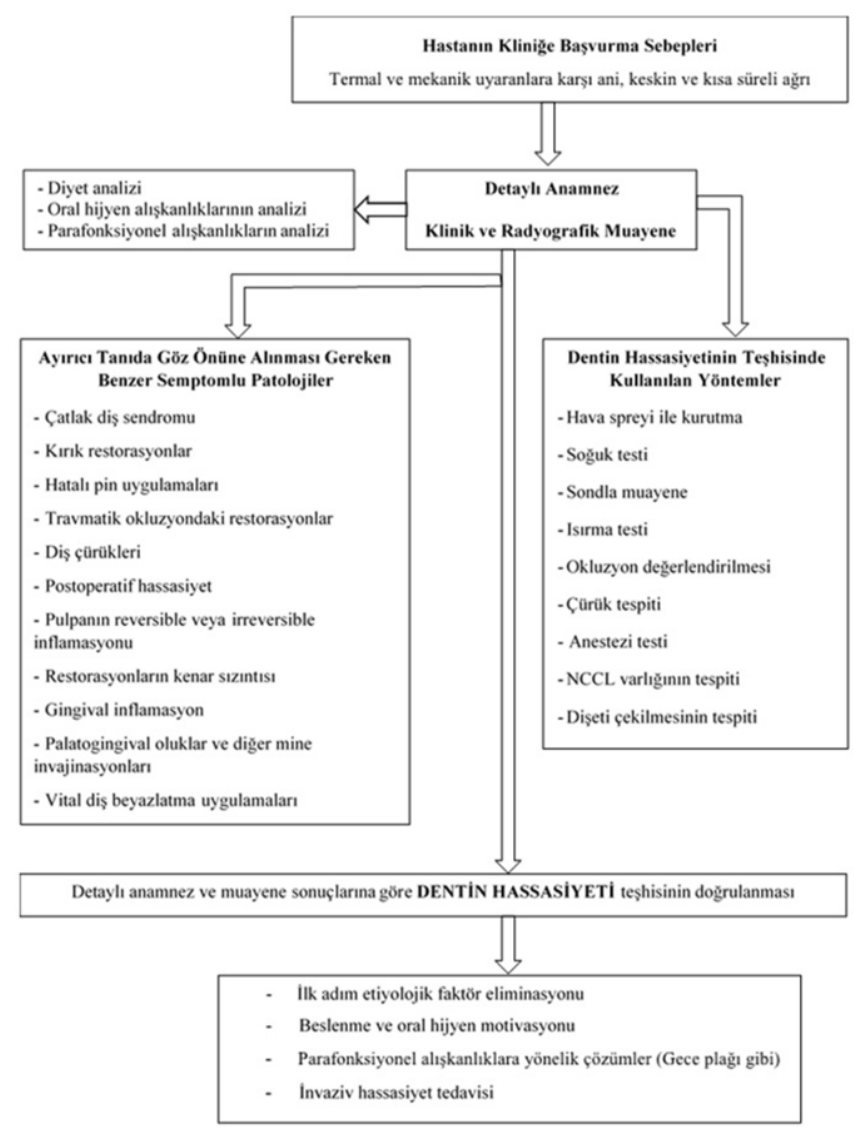

\section{SONUÇ}

Günümüzde görülme sıklığı giderek artan dentin hassasiyeti; yaşam kalitesini doğrudan etkileyen, kompleks bir semptomlar bütünüdür. Fakat tedavi seçenekleri halen tam olarak yeterli ve başarılı değildir. Bunun sebebi ise etiyolojisinin multifaktöriyel olması ve tedavi şeklinin sadece hastanın subjektif tepkilerine bağlı kalınarak belirlenebilmesidir. Ayrıca semptomlarının diğer dental defekt ve patolojilerle benzerlik göstermesi, klinik tanı ve teşhisini de zorlaştırmaktadır. Bu yüzden hastadan detaylı bir anamnez alınmalı ve iyi bir klinik muayene yapılmalıdır. Etiyoloji ve risk faktörlerinin erken teşhisi ve hassasiyete neden olan alışkanlıkların değiştirilmesi ya da tamamen terk edilmesi gibi yaklaşımlar dentin hassasiyetinin giderilmesinde ve tedaviden uzun dönemde sonuç alınmasında önemlidir. 


\section{KAYNAKLAR}

1. Kielbassa AM. Dentin hypersensitivity: Simple steps for everyday diagnosis and management. Int Dent J 2002;52(5):394-6.

2. Gilliam DG, Orchardson R. Advances in the treatment of root dentine sensitivity: mechanisms and treatmetn principles. Endodontic Topics 2006;13(1):13-33.

3. Absi EG, Addy M, Adams D. Dentine hypersensitivity. A study of the patency of dentinal tubules in sensitive and non-sensitive cervical dentine. J Clin Periodontol 1987;14(5):280-4.

4. Addy M. Dentine hypersensitivity: new perspectives on an old problem. Int Dent J 2002;52(5):375-87.

5. Canadian Advisory Board on Dentin Hypersensitivity. Consensus-based recommendations for the diagnosis and management of dentin hypersensitivity. J Can Dent Assoc 2003;69(4):221-6.

6. Pashley D, Hargreaves KM, Goodis HE. Seltzer and Bender's Dental Pulp. Quintessence Publishing; 2002. p. 63-93.

7. Dowell P, Addy M. Dentine hypersensitivity--a review. Aetiology, symptoms and theories of pain production. J Clin Periodontol 1983;10(4):341-50.

8. Yoshıyama M, Masada J, Uchıda A, Ishıda $H$. Scanning electron microscopic characterization of sensitive vs. Insensitive human radicular dentin. J Dent Res 1989;68(11):1498.

9. Gillam DG, Newman HN. Assessment of pain in cervical dentinal sensitivity studies. A review. J Clin Periodontol 1993;20(6):383-94.

10.Barsky AJ, Saintfort R, Rogers MP, Borus JF. Nonspecific medication side effects and the nocebo phenomenon JAMA 2002;287(5):622-7.

11. Ernst E. Placebo: New insights into an old enigma. Drug Discover Today 2007;12(9-10):413-8.

12. McCarney $R$, Warner J, lliffe $S$, van Haselen $R$, Griffin M, Fisher P. The Hawthorne Effect: a randomised, controlled trial. BMC MedResMethodol 2007;7(1):30.

13. Ye W, Feng XP, Li R. The prevalence of dentine hypersensitivity in Chinese adults. J Oral Rehabil 2012;39(3):182-7.

14. Gernhardt CR. How valid and applicable are current diagnostic criteria and assesment methods for dentin hypersensitivity An overview. Clin Oral Investig 2013;17:31-40.

15. Markowitz K. A new treatment alternative for sensitive teeth: A desensitizing oral rinse. J Dent 2013;41(1):1-11.

16. West XN, Sanz M, Lussi A, Bartlett D, Bouchard P, Bourgeois D. Prevelance of dentine hypersensitivity and study of associated factors: A European population-based cross-sectional study. J Dent 2013;41(1):841-51.
17.Addy M. Dentin hypersensitivity: definition, prevalence, distribution, aetiology. Addy $M$, Embry G, Edgar WM, Orchardson R, editors. Tooth wear and sensitivity: Clinical advances in restorative dentistry. Martin Dunitz Publication; 2000. p. 239-48.

18. Bartold P.Dentinal hypersensitivity: A review. Aust Dent J 2006;51(3):212-8.

19.Addy M. Etiology and clinical implications of dentine hypersensitivity. Dent Clin North Am 1990;34(3):503-14.

20.Dababneh $\mathrm{RH}$, Khouri AT, Addy M. Dentine hypersensitivity - an enigma A review of terminology, mechanisms, aetiology and management. Br Dent J 1999;187(1):606-11.

21.Drısko C. Dentine hypersensitivity-dental hygiene and periodontal considerations. Int Dent $J$ 2002;4(1):385-93.

22. Macgregor ID, Rugg-Gunn AJ. A survey of toothbrushing sequence in children and young adults. J Periodontal Res 1979;14(3):225-30.

23. Clayton DR, McCarthy D, Gillam DG. A study of the prevalence and distribution of dentine sensitivity in a population of 17-58-year-old serving personnel on an RAF base in the Midlands. J Oral Rehabil 2002;29(1):14-23.

24.Brännström M, Aström A. The hydrodynamics of the dentine; its possible relationship to dentinal pain. Int Dent J 1972;22(2):219-27.

25. Dowell P, Addy M. Dentine hypersensitivity-a review. Aetiology, symptoms and theories of pain production. $\mathrm{J}$ Clin Periodontol 1983;10(4):341.

26.Kramer IR. The relationship between dentine sensitivity and movements in the contents of dentinal tubules. Br Dent J 1955;98(1):391-2.

27. Brännström M, Johnson $G$. Movements of the dentine and pulp liquids on application of thermal stimuli. An in vitro study. Acta Odontol Scan 1970;28(1):59-70.

28. Närhi MV, Hirvonen T. The response of dog in tradental nerves to hypertonic solutions of $\mathrm{CaCl}_{2}$ and $\mathrm{NaCl}$, and other stimuli, applied to exposed dentine. Archs Oral Biol 1987;32(11):781-6.

29. Orchardson R, Gillam DG. Managing dentin hypersensitivity. J Am Dent Assoc 2006;137(7):990-8.

30.Porto IC, Andrade AK, Montes MA. Diagnosis and treatment of dentinal hypersensitivity. J Oral Sci 2009;51(3):323-32.

31. Miglani S, Aggarwal V, Ahuja B. Dentin hypersensitivity: Recent trends in management. J Conserv Dent 2010;13(4):218-24. 
32. Hall RC, Embery G, Shellis RP. Biological and structural features of enamel and dentine: current concepts relevant to erosion and dentine hypersensitivity. Addy M, Embry G, Edgar WM, Orchardson $\mathrm{R}$, editors. Tooth wear and sensitivity: Clinical advances in restorative dentistry. Martin Dunitz Publication; 2000. p. 15-62.

33. Orchardson R, Gangarosa LP, Holland GR, Pashley DH, Trowbridge HO, Ashley FP. Dentine hypersensitivity-into the 21st century. Archs Oral Biol 1994;39:113-9.

34.Lundy T, Stanley HR. Correlation of pulpal histopathology and clinical symptoms in human teeth subjected to experimental irritation. Oral Surg Oral Med Oral Pathol 1969;27(2):187-201.

35. Dowell P, Addy M, Dummer P. Dentine hypersensitivity: Aetiology, differential diagnosis and management. Br Dent J 1985;158(3):92.

36. Litonjua LA, Andreana S, Bush PJ, Cohen RE. Tooth wear: attrition, erosion, and abrasion. Quintessence Int 2003;34(6):435-46.

37. West NX. Dentine hypersensitivity: preventive and therapeutic approaches to treatment. Periodontol 20002008;48(1):31-41.

38.Zero DT, Lussi A. Etiology of enamel erosion: intrinsic and extrinsic factors. Addy M, Embry G, Edgar WM, Orchardson R, editors. Tooth wear and sensitivity: Clinical advances in restorative dentistry. Martin Dunitz Publication; 2000. p. 121 140.

39.Lussi A, Jaeggi T. Erosion--diagnosis and risk factors. Clin Oral Invest 2008;12(1):5-13.

40.Cummins D. Recent advances in dentin hypersensitivity: clinically proven treatments for instant and lasting sensitivity relief. Am J Dent 2010;23(A):3A-13A.

41. Löe $\mathrm{H}$, Ånerud $\AA$, Boysen $\mathrm{H}$. The natural history or periodontal disease in man: prevalence, severity and extent of gingival recession. J Periodontol 1992;63(6):489-95.

42. Krauser JT. Hypersensitive teeth. Part I: Etiology. J Prosthet Dent 1986;56(1):153-156.

43.Pashley DH. Mechanisms of dentin sensitivity. Dent Clin North Am 1990;34:449-73.

44.Addy M, Mostafa P, Newcombe RG. Dentine hypersensitivity: the distribution of recession, sensitivity and plaque. J Dent 1987;15(6):242-8.

45.Addy M. Clinical aspects of dentine hypersensitivity. Proc Finn Dent Soc 1992;88(1):23-30.

46. Trowbridge HO, Silver DR. A review of current approaches and in-office management of tooth hypersensitivity. Dental Clinics of North America 1990;34:561-81.
47. Haneet RK, Vandana LK. Prevalence of dentinal hypersensitivity and study of associated factors: a cross-sectional study based on the general dental population of Davangere, Karnataka, India. Int Dent J 2016;66(1):49-57.

48. Clement C Azodo, Awerosa C Amayo. Dentinal sensitivity among a selected group of young adults in Nigeria. Niger Med J 2011;52(3):18992.

49. Naidu GM, Ram KC, Sirisha NR, Sree YS, Kopuri RK, Satti NR, Thatimatla C. Prevalence of dentin hypersensitivity and related factors among adult patients visiting a dental school in Andhra Pradesh, Southern India. J Clin Diagn Res 2014;8(9):48-51.

50.Zakereyya SA, Maram KA. Prevalence and Pattern of Dentin Hypersensitivity in a Jordanian Population in Irbid City. Oral Hygiene \& Health Journal 2014;4(3):178-186.

51.Braimoh OB, llochonwu NA. Dentin hypersensitivity among undergraduates in a university community. S J Oral Sci 2014;5(5):15.

52. Rane P, Pujari S, Patel P, Gandhewar M, Madria K, Dhume S. Epidemiological Study to Evaluate the Prevalence of Dentine Hypersensitivity among Patients. J Int Oral Health 2013;5(5):15-9.

53. Vijaya V, Sanjay V, Varghese RK, Ravuri R, Agarwal A. Association of dentine hypersensitivity with different risk factors - a cross sectional study. J Int Oral Health 2013;5(6):88-92.

54.Khafaji Hasanain Al. Observations on dentine Hypersensitivity in general dental practices in the United Arab Emirates. Eur J Dent 2013;7(4):389-94.

55. Cunha-Cruz J, Wataha JC, Heaton LJ, Rothen M, Sobieraj M, Scott J, Berg J. Northwest Practice-Based Research Collaborative in Evidence-Based Dentistry. The prevalence of dentin hypersensitivity in general dental practices in the northwest United States. JADA 2013;144(3):288-96.

56.Wang Y, Que K, Lin L, Hu D, Li X. The prevalence of dentine hypersensitivity in the general population in China. J Oral Rehabil 2012;39(11):812-20.

57.Colak H, Aylıkçı BU, Hamidi MM, Uzgur R. Prevalence of dentine hypersensitivity among university students in Turkey. Niger $\mathrm{J}$ Clin Pract 2012a; 15(1):415-9. 
58. Colak H, Demirer S, Hamidi M, Uzgur R, Koseoğlu S. Prevalence of Dentine Hypersensitivity among Adult Patients Attending a Dental Hospital Clinic in Turkey. West Indian Med J 2012b;61(2):174-9.

59.Bahşi E, Dalli M, Uzgur R, Turkal M, Hamidi MM, Colak $H$. An analysis of the aetiology, prevalence and clinical features of dentine hypersensitivity in a general dental population. Eur Rev Med Pharmacol Sci 2012;16(8):1107-16.

60.Amarasena N, Spencer J, Ou Y, Brennan D. Dentine hypersensitivity in a private practice patient population in Australia. $\mathrm{J}$ Oral Rehabil 2011;38(1):52-60.

61.Bamise CT, Kolawole KA, Oloyede EO, Esan TA. Tooth sensitivity experience among residential university students. Int J Dent Hyg 2010;8(2):95100.

62.Kehua Q, Yingying F, Hong S, Menghong W, Deyu $H$, Xu F. A cross-sectional study of dentine hypersensitivity in China. Int Dent J 2009;59(6):37680.

63. Rees JS, Jin LJ, Lam S, Kudanowska I, Vowles R. The prevalence of dentine hypersensitivity in a hospital clinic population in Hong Kong. J Dent 2003;31(7):453-61.

Yazışma Adresi:

Arş.Gör.Fatma SAĞ GÜNGÖR

Necmettin Erbakan Üniversitesi

Diş Hekimliği Fakültesi

Restoratif Diş Tedavisi AD

Karaciğan Mah. Ankara Cad.

No: 74/A Karatay, Konya

Tel : + 903322200026

GSM : + 905056110073

Faks : + 903322200045

E-mail: dtfatmasag@gmail.com 